\title{
Supporting Information for Scalable Nucleic Acid Storage and Retrieval using Barcoded Microcapsules
}

\author{
James L. Banal ${ }^{1, *}$ and Mark Bathe ${ }^{1,2, *}$ \\ ${ }^{1}$ Department of Biological Engineering, Massachusetts Institute of Technology, Cambridge, MA 02139 \\ USA \\ ${ }^{2}$ Broad Institute of MIT and Harvard, Cambridge, MA 02142 USA
}

*Correspondence should be addressed to: jbanal@mit.edu and mark.bathe@mit.edu

\section{Table of Contents}

Supporting Information Section S1. General materials .................................................................2

Supporting Information Section S2. Nucleic acid encapsulation and barcoding .................................... 3

Supporting Information Section S3. Characterization of silica capsules .............................................. 4

Supporting Information Section S4. Fluorescence-activated sorting and recovery of encapsulated nucleic acid 5

Supporting Information Section S5. Primer-probe design for qPCR assays.......................................... 5

Supporting Information Section S6. qPCR assay panel............................................................... 7

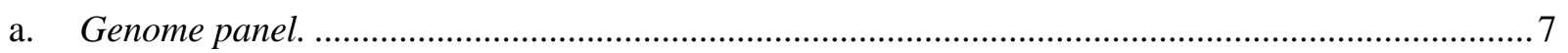

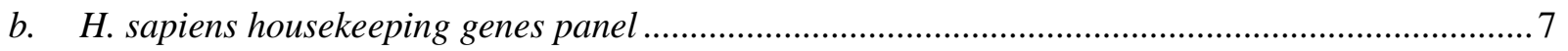

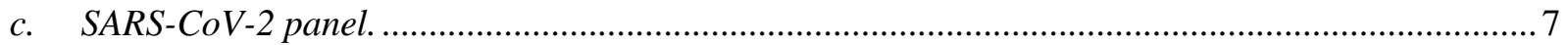

Supporting Information Section S7. Raw qPCR curve: retrieved supernatants from nucleic acid encapsulation 8

Supporting Information Section S8. Raw qPCR curves: discrete retrieval of single samples ................. 9

Supporting Information Section S9. Determining S. aureus genome content per unsorted capsule ........ 10

Supporting Information Section S10. Raw qPCR curves: retrieval of sample group using "Date 1" (200,000 capsules collected)

11

Supporting Information Section S11. Raw qPCR curves: retrieval of eukaryotic and non-human samples using Boolean logic (200,000 capsules collected)

Supporting Information Section S12. Raw qPCR curves: retrieval of $H$. sapiens capsules using Boolean logic (200,000 capsules collected) 13

Supporting Information Section S13. Sequencing validation ....................................................... 14

Supporting Information Section S14. Accelerated weathering of barcodes on microcapsules................ 15

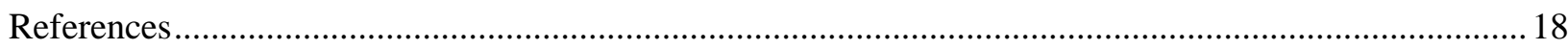




\section{Supporting Information Section S1. General materials}

All DNA sequences, including barcodes, fluorescently-labeled probes for capsule retrieval, primers-probe sets for qPCR, were obtained from Integrated DNA Technologies (IDT; Coralville, IA). Bovine (catalog number: 69231-3) and murine (catalog number: 69239-3) genomic DNA were obtained from Millipore Sigma (St. Louis, MO). Genomic DNA of S. aureus was obtained from ATCC (Manassas, VA; catalog number: BAA-2313DX). Total RNA was extracted from 1 million HEK293 cells using Trizol® (Invitrogen; catalog number: 15596026) and purified using Purelink ${ }^{\mathrm{TM}}$ RNA Mini Kit (Invitrogen; 12183020) following the manufacturer"s protocol, which includes a DNAse I (New England Biolabs or NEB; catalog number: M0303S) treatment step to remove genomic DNA. SARS-CoV-2 RNA genome was obtained from Twist Bioscience (San Francisco, CA; catalog number: 102019). Concentrations of all nucleic acids were determined using spectrophotometric method and monitoring the absorbance at $260 \mathrm{~nm}$.

Colloidal suspensions of non-porous, hydroxy-terminated 5- $\mu \mathrm{m}$ silica particles were obtained from Creative Diagnostics (Shirley, NY; catalog number: DNG-E029). Silica precursors, tetraethoxysilane (catalog number: 333859) and 3-aminopropyltriethoxysilane (catalog number: 440140), were purchased from Millipore Sigma (Allentown, PA) while $N$-[3-(trimethoxysilyl)propyl]- $N, N, N$-trimethylammonium chloride in 50\% methanol (catalog number: H66414) was obtained from Alfa Aesar and was used to convert the surface of hydroxy-terminated silica particles to trimethylammonium according to published procedures ${ }^{1}$. Anhydrous $N$-methyl-2-pyrrolidone was purchased through Millipore Sigma (catalog number: 270458). For surface functionalization of the encapsulated samples ${ }^{1}, 3$-aminopropyltriethoxysilane was purchased from Millipore Sigma (catalog number: 440140-100ML). DBCO-PEG 12 -TFP ester (DBCO: dibenzylcyclooctyne; PEG: poly(ethylene glycol); TFP: tetrafluorophenyl) used as a linker to attach aminomodified DNA barcodes to the surface of the capsules ${ }^{1}$ was obtained from Quanta Biodesign (Plain City, $\mathrm{OH}$; catalog number: 11366), dissolved in $1.0 \mathrm{~mL}$ of anhydrous $N$-methyl-2-pyrrolidone upon receipt, and stored in $-20^{\circ} \mathrm{C}$ until further use. 


\section{Supporting Information Section S2. Nucleic acid encapsulation and barcoding}

Encapsulation of nucleic acids and barcoding of capsules were performed according to the previously published procedures ${ }^{1}$. For each individual nucleic acid in 1.5-mL Eppendorf LoBind tubes, a volume of $10 \mu \mathrm{L}$ of bovine genomic DNA (100 ng $\left.\mu \mathrm{L}^{-1}\right)$, murine genomic DNA (100 ng $\left.\mu \mathrm{L}^{-1}\right)$, S. aureus genomic DNA (200 ng $\left.\mu \mathrm{L}^{-1}\right)$, total RNA from HEK293 cells $\left(1,000 \mathrm{ng} \mu \mathrm{L}^{-1}\right)$, and SARS-CoV-2 RNA genome $\left(1,000,000\right.$ copies $\left.\mu \mathrm{L}^{-1}\right)$ were encapsulated using $1.0 \mathrm{mg}$ of ammonium-functionalized silica particles suspended in $1 \mathrm{~mL}$ of nuclease-free water. Capsules were individually barcoded using 25-nucleotide singlestranded DNA strands selected from a library of 240,000 orthogonal primers ${ }^{2}$ and using barcode conjugation methods published previously ${ }^{1}$ (Supporting Information Table S1). Upon barcode labeling, all the sample capsules were pooled together and re-suspended in $40 \mathrm{mM}$ Tris, $20 \mathrm{mM}$ acetate, $2 \mathrm{mM}$ EDTA, $1.0 \%$ Tween-20, $1.0 \%$ sodium dodecyl sulfate and $500 \mathrm{mM} \mathrm{NaCl}$ to a final particle concentration of $1.0 \mathrm{mg} \mathrm{mL} \mathrm{m}^{-1}$.

Supporting Information Table S1. Barcodes. /5AmMC6/ is IDT"s modification code for 5"-amino modifications for DNA sequences.

\begin{tabular}{|c|c|c|c|c|}
\hline Organism & Tag 1 & Tag 2 & Tag 3 & Tag 4 \\
\hline Bos taurus & $\begin{array}{l}\text { Eukaryote: } \\
\text { /5AmMC6/AACGATTGTT } \\
\text { ATGCCCCTAACTCAG }\end{array}$ & $\begin{array}{l}\text { Animalia: } \\
\text { /5AmMC6/ATGGACGACT } \\
\text { TGGGACGGGTATCAA }\end{array}$ & $\begin{array}{l}\text { Bos taurus: } \\
\text { /5AmMC6/TAATGTGGCT } \\
\text { TGGCTCACCGCTAGG }\end{array}$ & $\begin{array}{l}\text { Date 1: } \\
\text { /5AmMC6/CGATGTAGTC } \\
\text { ATCCCGATGTGCTGG }\end{array}$ \\
\hline $\begin{array}{l}\text { Staphylococcus } \\
\text { aureus }\end{array}$ & $\begin{array}{l}\text { Bacteria: } \\
\text { /5AmMC6/GTAGTTCGGG } \\
\text { GTGCATACTACCTGA }\end{array}$ & $\begin{array}{l}\text { Firmicutes: } \\
\text { /5AmMC6/GAGATTATTT } \\
\text { CCTCGTTCGGCCCAG }\end{array}$ & $\begin{array}{l}\text { S. aureus } \\
\text { /5AmMC6/AGTTAAATGT } \\
\text { CCCAGGCTTGTCACC }\end{array}$ & $\begin{array}{l}\text { Date 1: } \\
\text { /5AmMC6/CGATGTAGTC } \\
\text { ATCCCGATGTGCTGG }\end{array}$ \\
\hline Hom & $\begin{array}{l}\text { Eukaryote: } \\
\text { /5AmMC6/AACGATTGTT } \\
\text { ATGCCCCTAACTCAG }\end{array}$ & $\begin{array}{l}\text { Animalia: } \\
\text { /5AmMC6/ATGGACGACT } \\
\text { TGGGACGGGTATCAA }\end{array}$ & $\begin{array}{l}\text { Homo sapiens: } \\
\text { /5AmMC6/AAAAGCAAGG } \\
\text { TCGTTACATGGAGTT }\end{array}$ & $\begin{array}{l}\text { Date 2: } \\
\text { /5AmMC6/CTGGTTTGAT } \\
\text { CCGACACATTGATTC }\end{array}$ \\
\hline Mus musculus & $\begin{array}{l}\text { Eukaryote: } \\
\text { /5AmMC6/AACGATTGTT } \\
\text { ATGCCCCTAACTCAG }\end{array}$ & $\begin{array}{l}\text { Animalia: } \\
\text { /5AmMC6/ATGGACGACT } \\
\text { TGGGACGGGTATCAA }\end{array}$ & $\begin{array}{l}\text { Mus musculus: } \\
\text { /5AmMC6/GAACTTATTC } \\
\text { GGTATCTGTGCCGCT }\end{array}$ & $\begin{array}{l}\text { Date 2: } \\
\text { /5AmMC6/CTGGTTTGAT } \\
\text { CCGACACATTGATTC }\end{array}$ \\
\hline$S A R S-C o V-2$ & $\begin{array}{l}\text { Riboviria: } \\
\text { /5AmMC6/TTCAGGGTGG } \\
\text { AAGTACCTCCCAGAT }\end{array}$ & $\begin{array}{l}\text { Orthornavirae: } \\
\text { /5AmMC6/ACTCCGAGGA } \\
\text { ACTTCGTGCTTAGTG }\end{array}$ & $\begin{array}{l}\text { SARS-CoV-2: } \\
\text { /5AmMC6/CTGAATACTA } \\
\text { CACGCCGTGGTGAAG }\end{array}$ & $\begin{array}{l}\text { Date 3: } \\
\text { /5AmMC6/ATCTATCTGT } \\
\text { TGGAGTTAACGTACC }\end{array}$ \\
\hline
\end{tabular}




\section{Supporting Information Section S3. Characterization of silica capsules}

Micrographs of the silica capsules were taken using a Zeiss Gemini 2 field emission scanning electron microscope. Samples were mounted on glass slide cleaned with piranha solution and silicon substrates. Glass mounted samples were sputtered with gold $(<5 \mathrm{~nm})$ prior to imaging. Particle diameters were measured from seven widefield images taken from three independent replicates using Fiji.

a

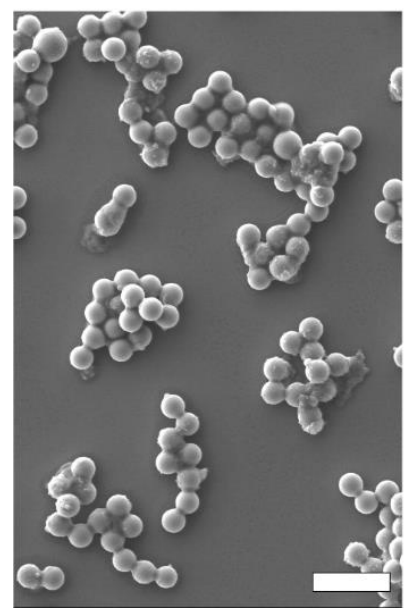

b

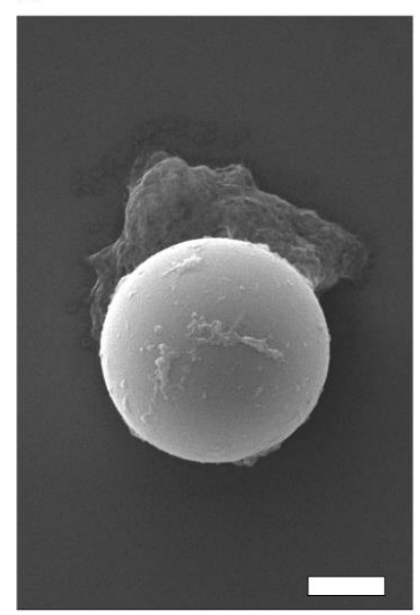

C

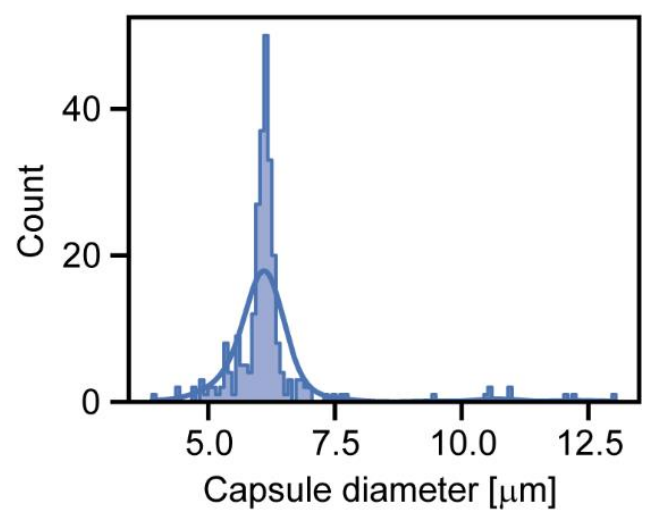

Supporting Information Figure S1. Scanning electron microscopy of DNA-labeled silica capsule library. Widefield (a) and single-particle (b) scanning electron micrographs. Scale bars: (a) $20 \mu \mathrm{m}$ and (b) $2 \mu \mathrm{m}$. (c) Histogram of DNA-labeled capsule diameters determined from scanning electron micrographs. Solid line is a univariate kernel density estimate of the measured capsule diameters.

Dynamic light scattering (DLS) measurements of silica capsules were performed using a Malvern Zetasizer Ultra. Samples for DLS (1 mg mL$~^{-1}$ in water) were measured in a UV-transparent disposable micro cuvettes (Sarstedt; catalog number: 67.758). Zeta potential measurements were also performed using a Malvern Zetasizer Ultra with the universal dip-cell accessory (Malvern Panalytical; catalog number: ZEN1002). Samples for zeta potential measurements $\left(1 \mathrm{mg} \mathrm{mL}^{-1}\right.$ in water) were measured in disposable cuvettes (Sarstedt; catalog number: 67.754).

a

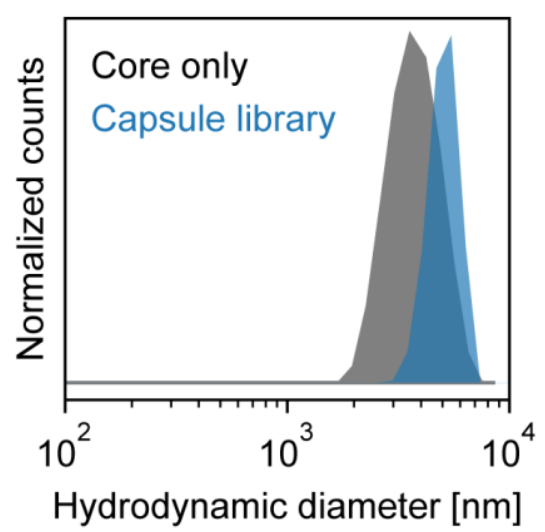

b

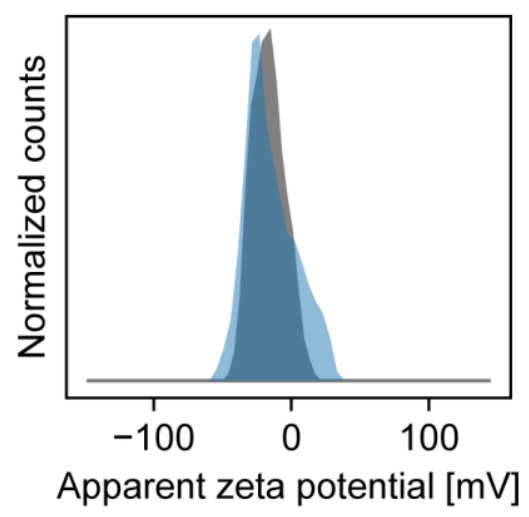

Supporting Information Figure S2. Dynamic light scattering characterization of capsule library. (a) hydrodynamic diameter and (b) zeta potential of the capsule library and core particles using water as solvent. 


\section{Supporting Information Section S4. Fluorescence-activated sorting and recovery of encapsulated nucleic acid}

Sample selection using fluorescently-labeled probes. The sample library was vortexed for 10 seconds to re-disperse the settled particles. A volume of $200 \mu \mathrm{L}$ of the sample library $\left(1 \mathrm{mg} \mathrm{mL}^{-1}\right)$ was added into a 1.5-mL Eppendorf LoBind tube. Dye-labeled probes for querying the molecular file database (Supporting Information Table S2) were added such that the final concentration of the DNA-dye single-stranded DNA in solution is $5 \mu \mathrm{M}$. The resulting mixtures were mixed at $25^{\circ} \mathrm{C}$ at 1,200 -rpm using a thermal mixer for 5 minutes. The mixtures were then centrifuged at $10,000 \mathrm{~g}$ for 1 minute. The supernatant was discarded, and the pelleted particles were washed with $500 \mu \mathrm{L}$ of $40 \mathrm{mM}$ Tris, $20 \mathrm{mM}$ acetate, $2 \mathrm{mM}$ EDTA, $1.0 \%$ Tween$20,1.0 \%$ sodium dodecyl sulfate, and $500 \mathrm{mM} \mathrm{NaCl}$. The sedimentation and washing process was repeated five additional times to remove non-specifically bound fluorescent probes. The particles were finally resuspended in $500 \mu \mathrm{L}$ of $40 \mathrm{mM}$ Tris, $20 \mathrm{mM}$ acetate, $2 \mathrm{mM}$ EDTA, 1.0\% Tween-20, $1.0 \%$ sodium dodecyl sulfate, $500 \mathrm{mM} \mathrm{NaCl}$.

Supporting Information Table S2. Fluorescently labeled probes for capsule selection. /56-FAM/, /56-TAMN/, /5Alex647N/, and /5TYE705/ are IDT"s modification codes for fluorescein, tetramethylrhodamine, Alexa Fluor 647 , and TYE 705 dyes, respectively. The concentration of all probes was normalized to $100 \mu \mathrm{M}$ in water using the molar absorption coefficient of the dyes.

\begin{tabular}{|l|l|}
\hline Query probe & Sequence \\
\hline "Eukaryote" & /5Alex647N/CTGAGTTAGGGGCAT \\
\hline "S. aureus" & /5Alex647N/GGTGACAAGCCTGGG \\
\hline "Animalia" & /56-TAMN/TTGATACCCGTCCCA \\
\hline "Date 1" & /56-FAM/CCAGCACATCGGGAT \\
\hline "H. sapiens" & /5TYE705/AACTCCATGTAACGA \\
\hline
\end{tabular}

Fluorescence-activated sorting. All fluorescence-activated sorting (FAS) experiments were performed on a BD FACSAria III flow cytometer. Samples were flowed into the instrument with $1 \times$ PBS as sheath fluid at a flow rate that maintains an events detection rate of 5,000 events per second and below to avoid clogging the instrument. All sorts were accomplished with a $70-\mu \mathrm{m}$ nozzle. Untreated sample library $\left(1 \mathrm{mg} \mathrm{mL}^{-1}\right.$ in $40 \mathrm{mM}$ Tris, $20 \mathrm{mM}$ acetate, $2 \mathrm{mM}$ EDTA, 1.0\% Tween-20, 1.0\% sodium dodecyl sulfate and $500 \mathrm{mM}$ $\mathrm{NaCl}$ ) were ran as negative controls and the resulting particle population plot was used to draw the forward scattering and side scattering gates to minimize the sorting of doublets. Single-color controls were ran as controls to draw sorting gates using the fluorescence channels. All FAS experiments were performed at room temperature. Sorted populations were collected in 1.5-mL Eppendorf LoBind tubes. All sorting experiments were performed in triplicates.

Reverse encapsulation and cleanup. Sorted populations were centrifuged at 20,000 $g$ for 1 minute. The supernatant was carefully removed with a pipette to avoid disturbing the silica pellets. A volume of $5 \mu \mathrm{L}$ of 10:1 buffered oxide etch (Avantor; Visalia, CA; catalog number: JT5175-03) was used to dissolve the sorted silica particles. The mixture was gently mixed using a pipette to re-suspend the pellet and was statically incubated at room temperature for 5 minutes. A volume of $45 \mu \mathrm{L}$ of $125 \mathrm{mM}$ phosphate buffer $\left(1.1 \% \mathrm{w} / \mathrm{w} \mathrm{Na} \mathrm{Na}_{2} \mathrm{HPO}\right.$ and $\left.0.6 \% \mathrm{w} / \mathrm{w} \mathrm{NaH}_{2} \mathrm{PO}_{4}\right)$ was then added and briefly vortexed. The resulting mixture was finally desalted through an Illustra MicroSpin S-200 HR column (Millipore Sigma; catalog number: GE27-5120-01). Released samples were stored at $-20^{\circ} \mathrm{C}$ when not in use.

\section{Supporting Information Section S5. Primer-probe design for qPCR assays}

Primers and probes for Bos taurus, Mus musculus, and Staphylococcus aureus genomes were designed using PrimerQuest tool from IDT using GenBank accession numbers as input sequences. The orthogonality of the primer pairs against non-target sequences was validated using Primer-BLAST from $\mathrm{NCBI}^{3}$ using the 
"Refseq representative genomes" option, which includes "Homo sapiens", "SARS-CoV-2 (taxid: 267049)", "Bos Taurus (taxid: 9913)", "Mus musculus (taxid: 10090)", and "Escherichia coli (taxid:562)". All probes feature a fluorescein (FAM) dye attached at the 5"-end as fluorescence reporter and a double quencher, an internal quencher $\left(\mathrm{ZEN}^{\mathrm{TM}}\right.$ ) and a 3"-terminal quencher (Iowa Black® ${ }^{\circledR} \mathrm{FQ}$ ), to reduce background fluorescence.

Predesigned PrimeTime ${ }^{\circledR}$ qPCR primer-probe mixes were obtained from IDT to detect housekeeping genes, GAPDH (assay ID: Hs.PT.39a.22214836; GenBank accession number: NM_002046; denoted herein as "H2" for brevity) and ACTB (assay ID: Hs.PT.39a.22214847; GenBank accession number: NM_001101; denoted herein as "H2" for brevity). SARS-CoV-2 qPCR primers and probes were from the 2019-nCOV research-use only kits from IDT (catalog number: 10006713). All SARS-CoV-2 samples were tested using the nCOV_N1 and nCOV_N2 primer-probe set, abbreviated herein as "N1" and "N2" for brevity.

Supporting Information Table S3. Primer-probe sets used for qPCR assays. /56FAM/, /ZEN/, and / 3IABkFQ/ are IDT"s modification codes for FAM, ZEN ${ }^{\mathrm{TM}}$, and Iowa Black® FQ dyes, respectively. Alphanumeric values in parentheses are primer codes used herein for brevity.

\begin{tabular}{|c|c|c|}
\hline Organism & $\begin{array}{l}\text { GenBank } \\
\text { accession number }\end{array}$ & Sequence \\
\hline \multirow[t]{6}{*}{ Bos taurus } & \multirow[t]{3}{*}{$\begin{array}{l}\text { V00654.1 } \\
\text { (B1) }\end{array}$} & $\begin{array}{l}\text { Forward: } \\
\text { GATGATACGGACGAGCAGATG }\end{array}$ \\
\hline & & $\begin{array}{l}\text { Reverse: } \\
\text { CTGTTGGAGGTCTCAGGTATTG }\end{array}$ \\
\hline & & $\begin{array}{l}\text { Probe: } \\
\text { /56-FAM/ACACAGCAG/ZEN/CCCTACAAGCAATCT/3IABkFQ/ }\end{array}$ \\
\hline & \multirow[t]{3}{*}{$\begin{array}{l}\text { GU249568.1 } \\
\text { (B2) }\end{array}$} & $\begin{array}{l}\text { Forward: } \\
\text { ACTAGCCCTAGCCTTCTCTATC }\end{array}$ \\
\hline & & $\begin{array}{l}\text { Reverse: } \\
\text { TCTGCTACTAGGGCTCAGAATA }\end{array}$ \\
\hline & & $\begin{array}{l}\text { Probe: } \\
\text { /56FAM/TATTCCGAC/ZEN/CACTCAGCCAATGCC/3IABkFQ/ }\end{array}$ \\
\hline \multirow[t]{6}{*}{$\begin{array}{l}\text { Staphylococcus } \\
\text { aureus }\end{array}$} & \multirow[t]{3}{*}{ AB201418.1 (S1) } & $\begin{array}{l}\text { Forward: } \\
\text { TCCACATGCAGCGAGTTTAG }\end{array}$ \\
\hline & & $\begin{array}{l}\text { Reverse: } \\
\text { TTCCTAAACCAACACCTCCATAG }\end{array}$ \\
\hline & & $\begin{array}{l}\text { Probe: } \\
\text { /56-FAM/AAGCACCAG/ZEN/CCAAAGCGTACAATC/3IABkFQ/ }\end{array}$ \\
\hline & \multirow[t]{3}{*}{$\begin{array}{l}\text { NG_047955.1 } \\
(\mathrm{S} 2)\end{array}$} & $\begin{array}{l}\text { Forward: } \\
\text { CCCGCATTGCATTAGCATTAG }\end{array}$ \\
\hline & & $\begin{array}{l}\text { Reverse: } \\
\text { AAGGGATAATCACTCGGGATATTT }\end{array}$ \\
\hline & & $\begin{array}{l}\text { Probe: } \\
\text { /56-FAM/AGGTATGCA/ZEN/AGATTTGGGAATCGGTGA/3IABkFQ/ }\end{array}$ \\
\hline \multirow[t]{6}{*}{ Mus musculus } & \multirow[t]{3}{*}{$\begin{array}{l}\text { NC_005089.1 } \\
(\mathrm{M} 1)\end{array}$} & $\begin{array}{l}\text { Forward: } \\
\text { AGGTTATTAGGGTGGCAGAG }\end{array}$ \\
\hline & & $\begin{array}{l}\text { Reverse: } \\
\text { GGACGAGGAGTGTTAGGATATT }\end{array}$ \\
\hline & & $\begin{array}{l}\text { Probe: } \\
\text { /56-FAM/ACCTTGTTC/ZEN/CCAGAGGTTCAAATCCT/3IABkFQ/ }\end{array}$ \\
\hline & \multirow[t]{3}{*}{ J01420.1 (M2) } & $\begin{array}{l}\text { Forward: } \\
\text { GGAACAACCCTAGTCGAATGAA }\end{array}$ \\
\hline & & $\begin{array}{l}\text { Reverse: } \\
\text { GCTAGGGCCGCGATAATAAA }\end{array}$ \\
\hline & & $\begin{array}{l}\text { Probe: } \\
\text { /56-FAM/ACAAAGCCA/ZEN/CCTTGACCCGATTCT/3IABkFQ/ }\end{array}$ \\
\hline
\end{tabular}




\section{Supporting Information Section S6. qPCR assay panel}

\section{a. Genome panel.}

In a 384-well microplate, a volume of $1 \mu \mathrm{L}$ of positive control or unknown sample were added to a well that contains $5 \mu \mathrm{L}$ of $2 \times$ NEB Luna ${ }^{\circledR}$ Universal Probe qPCR Master Mix (catalog number: M3004X), $0.5 \mu \mathrm{L}$ of $10 \mu \mathrm{M}$ of primer pair, $0.5 \mu \mathrm{L}$ of $5 \mu \mathrm{M}$ of the probe (B1 or B2 for B. taurus; M1 and M2 for M. musculus; S1 and S2 for S. aureus), and $3 \mu \mathrm{L}$ of nuclease-free water. Real-time qPCR was performed with an Applied Biosystems QuantStudio 7 Flex RT-PCR and using the suggested protocol from NEB: $95{ }^{\circ} \mathrm{C}$ for 1 minute (initial denaturation), then 45 cycles of $95{ }^{\circ} \mathrm{C}$ for 15 seconds (denaturation) and $60^{\circ} \mathrm{C}$ for 30 seconds (annealing/extension), including plate read.

\section{b. H. sapiens housekeeping genes panel}

Step 1. cDNA conversion:

A mass of $1 \mu \mathrm{g}$ of total RNA from HEK293 cells as positive control or $10 \mu \mathrm{L}$ of unknown sample were reverse transcribed using SuperScript ${ }^{\circledR}$ IV Reverse Transcriptase (Invitrogen; catalog number: 18090050) and ReadyMade ${ }^{\mathrm{TM}}$ random hexamers (IDT; catalog number: 51-01-18-25) as universal primers following manufacturer"s protocol, which includes an RNA removal step with $1 \mu \mathrm{L}$ of $E$. coli RNAse H (Life Technologies, Carlsbad, CA; catalog number: 18021014) after reverse transcription.

Step 2. qPCR assay:

In a 384-well microplate, a volume of $1 \mu \mathrm{L}$ of reverse-transcribed cDNA was added to a well that contains $5 \mu \mathrm{L}$ of $2 \times 2 \times$ NEB Luna ${ }^{\circledR}$ Universal Probe qPCR Master Mix, $0.5 \mu \mathrm{L}$ of $20 \times$ of PrimeTime ${ }^{\circledR}$ qPCR primer-probe mix ( $\mathrm{H} 1$ or $\mathrm{H} 2$ ), and $3.5 \mu \mathrm{L}$ of nuclease-free water. Real-time qPCR amplification was performed with an Applied Biosystems QuantStudio 7 Flex RT-PCR and using the suggested protocol from IDT: $95{ }^{\circ} \mathrm{C}$ for 3 minutes (polymerase activation) then 45 cycles of $95{ }^{\circ} \mathrm{C}$ for 5 seconds (denaturation), then $60{ }^{\circ} \mathrm{C}$ for 30 seconds (annealing/extension), including plate read.

\section{c. SARS-CoV-2 panel.}

In a 384-well microplate, a volume of $1 \mu \mathrm{L}$ of the unknown sample was added to a well that contains $5 \mu \mathrm{L}$ of NEB $2 \times$ Luna ${ }^{\circledR}$ Universal One-Step RT-qPCR Master Mix (catalog number: E3006S), $0.5 \mu \mathrm{L}$ of Luna ${ }^{\circledR}$ WarmStart ${ }^{\circledR}$ Reverse Transcriptase, $0.75 \mu \mathrm{L}$ of $\mathrm{N} 1$ or $\mathrm{N} 2$ primer set, and $2.75 \mu \mathrm{L}$ of nucleasefree water. One-step RT-qPCR amplification was performed with an Applied Biosystems QuantStudio 7 Flex RT-PCR and using the suggested protocol from NEB: $55{ }^{\circ} \mathrm{C}$ for 10 minutes (reverse transcription), $95{ }^{\circ} \mathrm{C}$ for 1 minute (initial denaturation), then 45 cycles of $95{ }^{\circ} \mathrm{C}$ for 10 seconds (denaturation), then $60^{\circ} \mathrm{C}$ for 30 seconds (annealing/extension), including plate read. 


\section{Supporting Information Section S7. Raw qPCR curve: retrieved supernatants from nucleic acid encapsulation}

Supernatants from post-encapsulation of nucleic acids were subjected to qPCR analyses using methods described in the "qPCR assay panel" section. All encapsulation supernatants did not lead to any appreciable amplification relative to the negative, no-template controls (Supporting Information Figure S3), suggesting that the encapsulation process is quantitative.
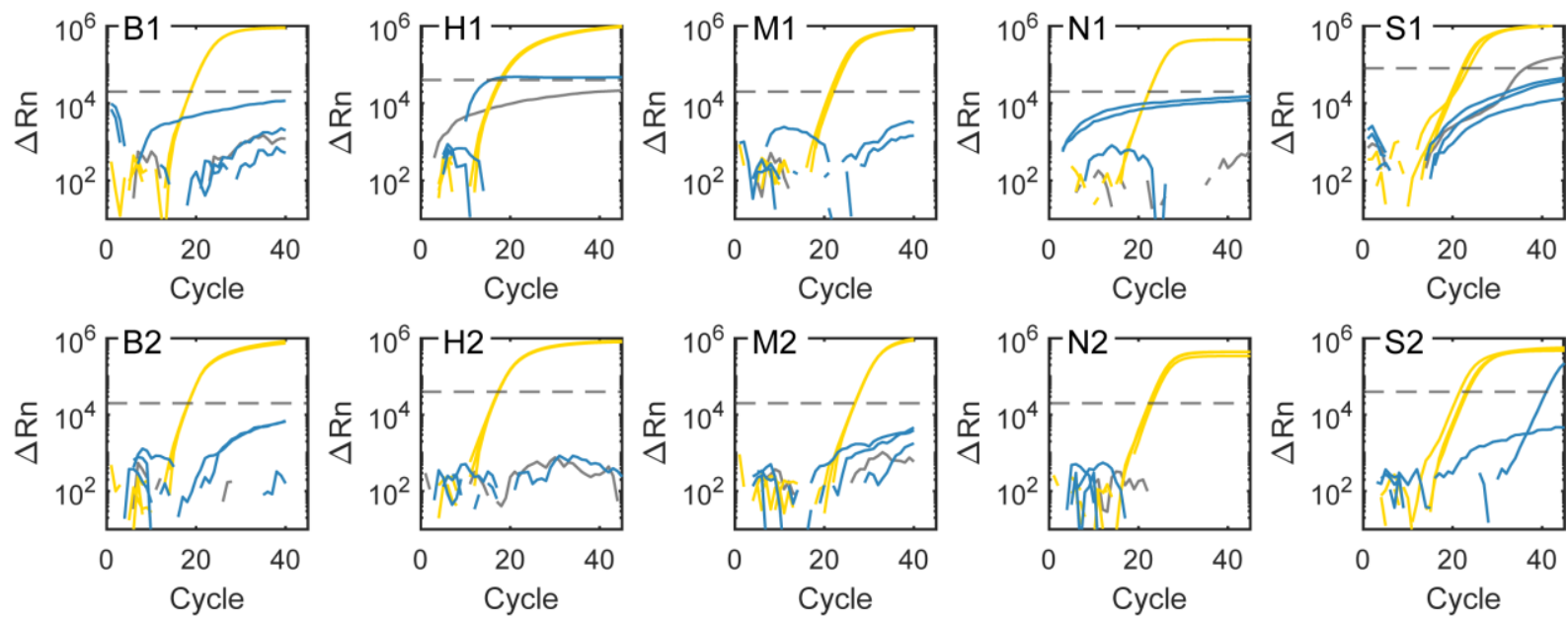

Supporting Information Figure S3. qPCR analyses of supernatants retrieved from post-encapsulation of nucleic acid samples. Solid gray lines are qPCR curves from negative, no-template controls. Horizontal broken lines are amplification thresholds automatically calculated by the Quantstudio software. Yellow lines are positive controls while blue lines are from aliquots of post-encapsulation supernatants. 
Supporting Information Section S8. Raw qPCR curves: discrete retrieval of single samples

a
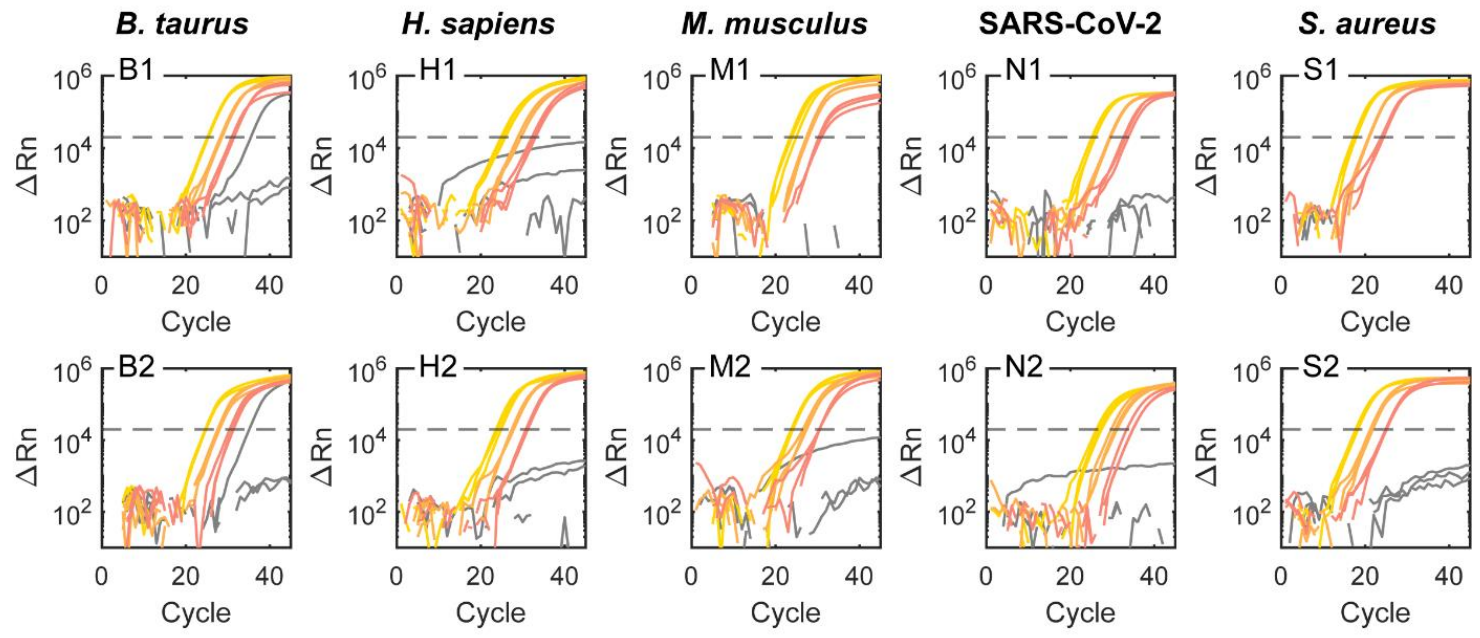

b
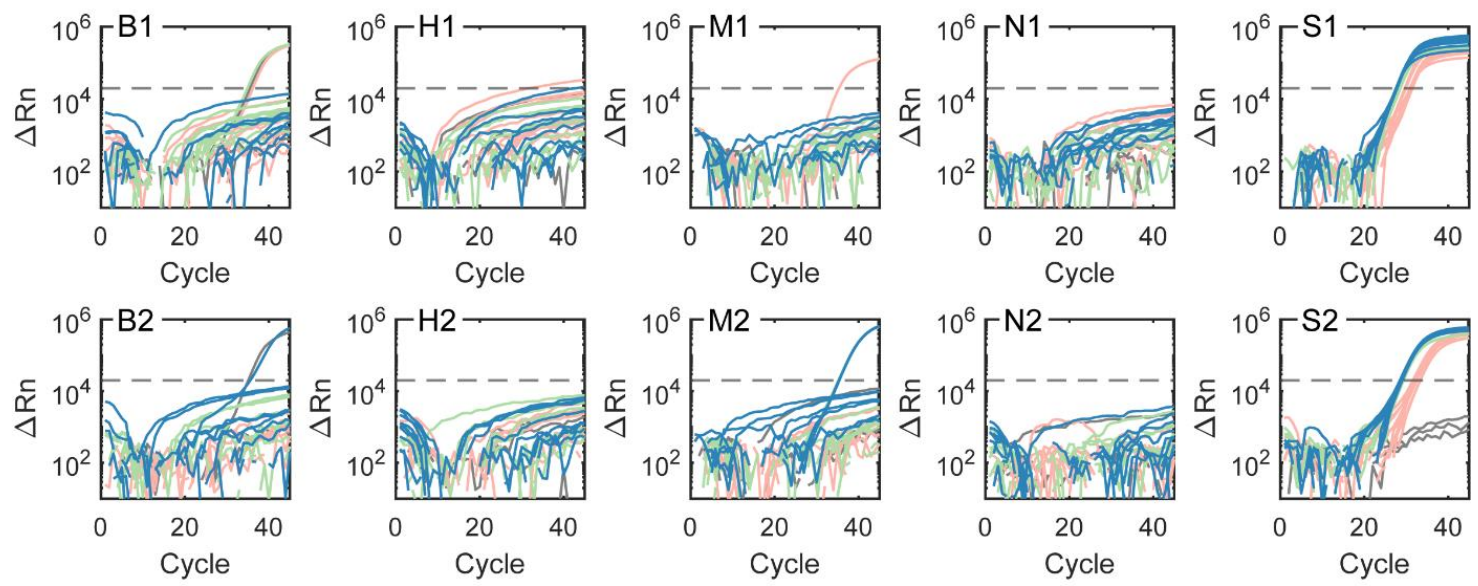

c
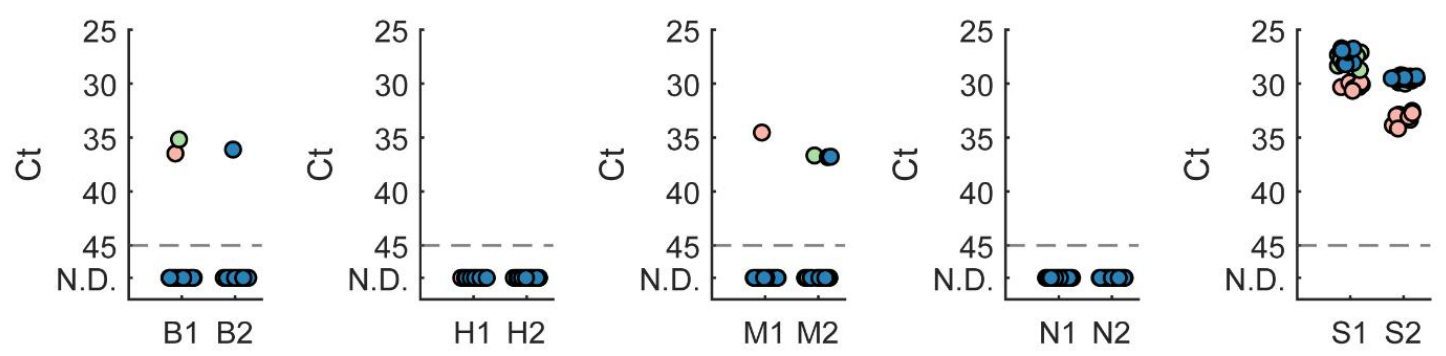

Supporting Information Figure S4. Raw qPCR data of single-sample retrieval experiments. (a) Solid gray lines are no-template controls. Positive controls are different concentrations of template nucleic acid. Horizontal broken lines are amplification thresholds automatically calculated by the Quantstudio software. For Bos taurus: $15 \mathrm{ng}, 1.5$ ng, 0.15 ng. For Staphylococcus aureus and Mus musculus: $10 \mathrm{ng}, 1.0 \mathrm{ng}, 0.10 \mathrm{ng}$. For Homo sapiens: $80 \mathrm{ng}, 8.0 \mathrm{ng}$, $0.80 \mathrm{ng}$ of cDNA from total RNA extracted from HEK293 cells. For SARS-CoV-2: $10^{5}, 10^{4}, 10^{3}$ viral RNA copies. (b) qPCR panel assay of retrieved S. aureus samples: $1 \times 10^{5}, 1.5 \times 10^{5}$, and $2 \times 10^{5}$ collected particles using FAS from the sample library. (c) Ct values calculated by the Quantstudio software. Each technical replicate (a total of three independent technical replicates) was measured in triplicates. N.D., no detected Ct. 


\section{Supporting Information Section S9. Determining S. aureus genome content per unsorted capsule}

A volume of $10,20,30,40$, and $50 \mu \mathrm{L}$ of unsorted $S$. aureus capsules $\left(1 \mathrm{mg} \mathrm{mL}^{-1}\right.$ stock) were released from encapsulation as described in the "Reverse encapsulation and cleanup" section. A particle concentration of $1 \mathrm{mg} \mathrm{mL}^{-1}$ capsules was measured to be equivalent to $4.3 \times 10^{5}$ capsules $\mathrm{mL}^{-1}$ using multiangle dynamic light scattering with a Malvern Zetasizer Ultra instrument and using water as solvent. $\mathrm{Ct}$ values measured using real-time qPCR and using S1 and S2 primers designed for S. aureus were converted to mass values using 10-fold dilutions of unencapsulated $S$. aureus genomes as standards (Supporting Information Figure S5a-c), which gave an average $S$. aureus genome per capsule of $4.1 \pm 2.3 \mathrm{fg}$ capsule $^{-1}$ (mean \pm standard deviation; $\mathrm{n}=30$ ) (Supporting Information Figure S5d)

a
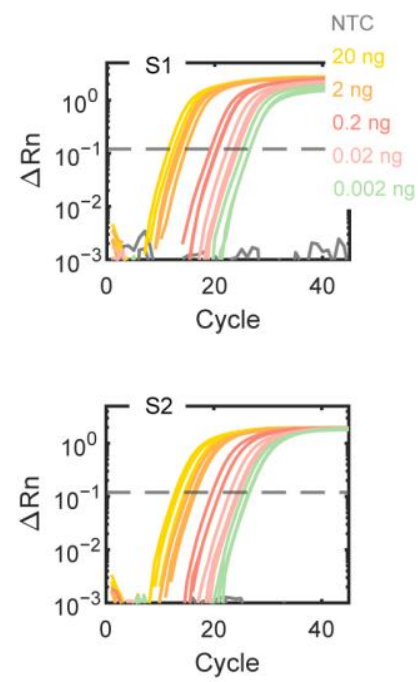

b
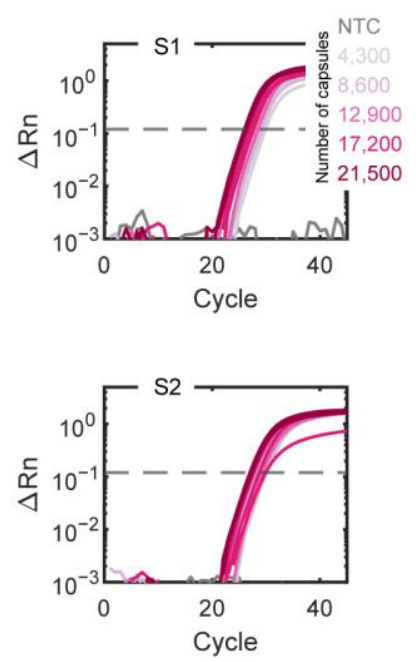

C

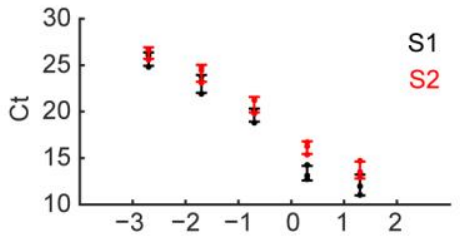

$\log _{10}$ S. aureus genome [ng]

d

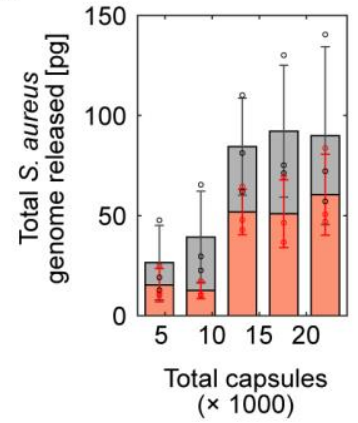

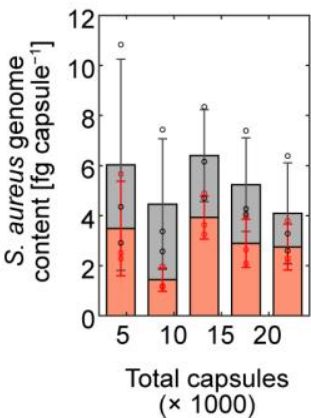

Supporting Information Figure S5. Quantifying the amount of $S$. aureus genomes per capsule. Raw qPCR curves of standards (a) and (b) samples. (c) Calibration curves generated using the two primer sets for S. aureus, namely S1 and S2. (d) Quantity of S. aureus genomes expressed as total S. aureus genomes released in pg as a function of total capsules de-encapsulated (left) and fg capsule ${ }^{-1}$ (right). Black circles and bars are genome quantities determined using $\mathrm{S} 1$ primers, while red circles and bars denote genome quantities determined using the S2 primers. Bar height indicates the average value determined from three independent replicates. Error bars are standard deviations calculated from three independent replicates. Circles are raw data points of each independent replicate. 

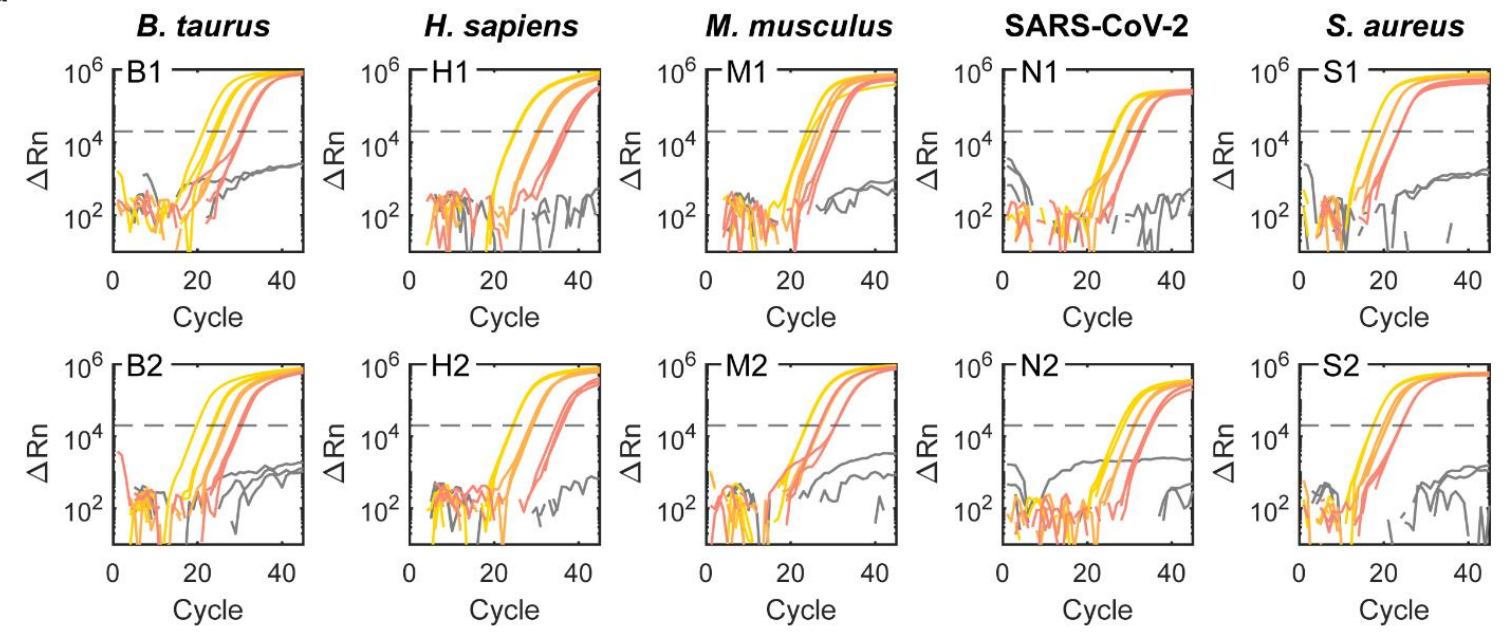

b
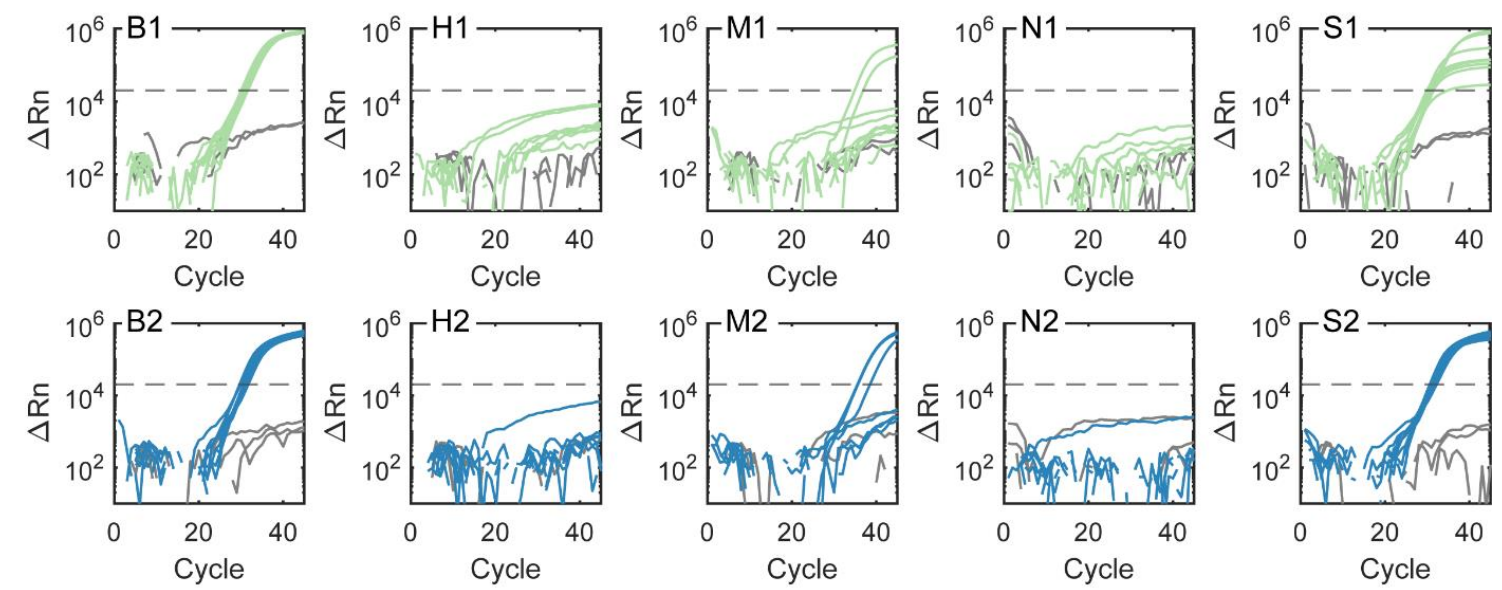

C
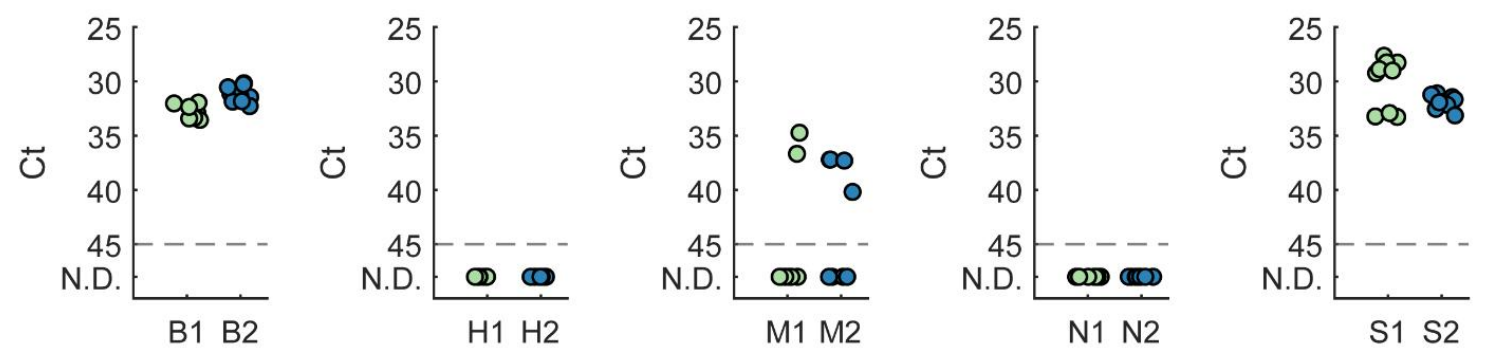

Supporting Information Figure S6. Raw qPCR data of "Date 1" retrieval experiments. (a) Solid gray lines are no-template controls. Positive controls are different concentrations of template nucleic acid. Horizontal broken lines are amplification thresholds automatically calculated by the Quantstudio software. For Bos taurus: $15 \mathrm{ng}, 1.5 \mathrm{ng}, 0.15$ ng. For Staphylococcus aureus and Mus musculus: $10 \mathrm{ng}, 1.0 \mathrm{ng}, 0.10 \mathrm{ng}$. For Homo sapiens: $80 \mathrm{ng}, 8.0 \mathrm{ng}, 0.80 \mathrm{ng}$ of cDNA from total RNA extracted from HEK293 cells. For SARS-CoV-2: $10^{5}, 10^{4}, 10^{3}$ viral RNA copies. (b) qPCR panel assay of retrieved sample group using FAS from the sample library. (c) Ct values calculated by the Quantstudio software. Each technical replicate (a total of three independent technical replicates) was measured in triplicates. N.D., no detected $\mathrm{Ct}$. 
Supporting Information Section S11. Raw qPCR curves: retrieval of eukaryotic and non-human samples using Boolean logic ( 200,000 capsules collected)

a
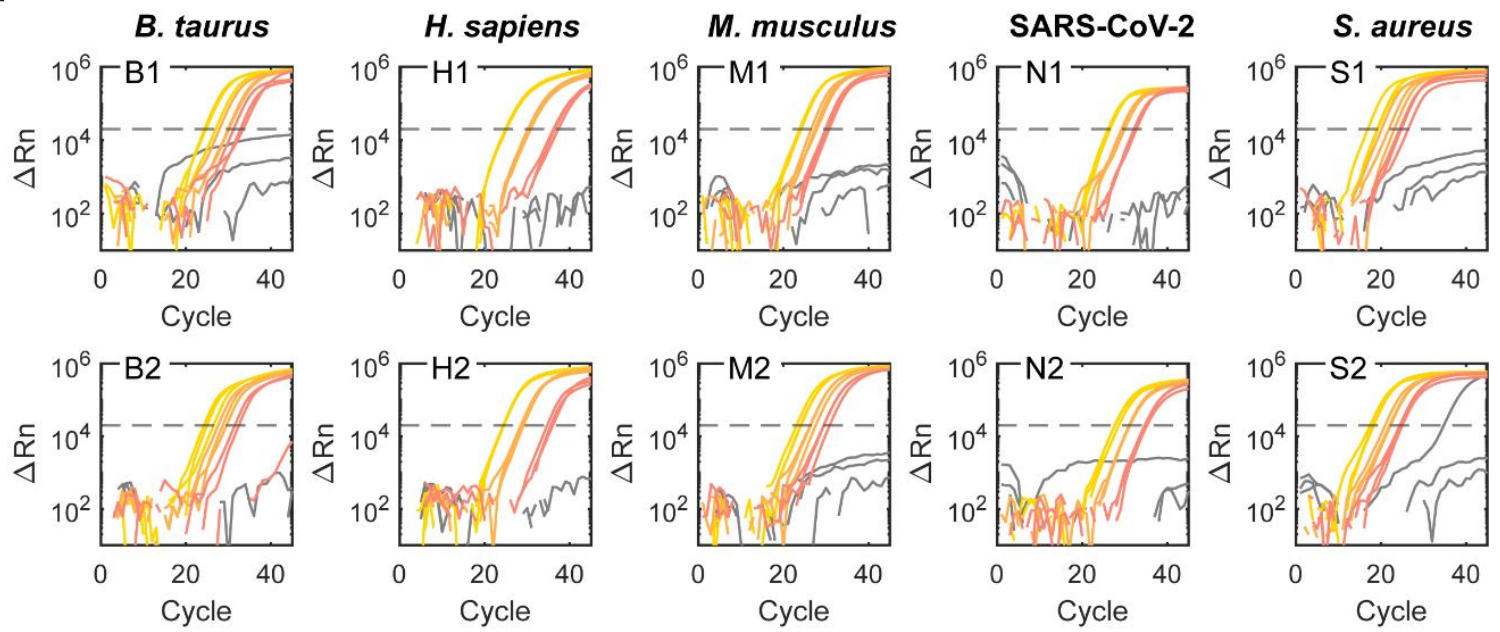

b
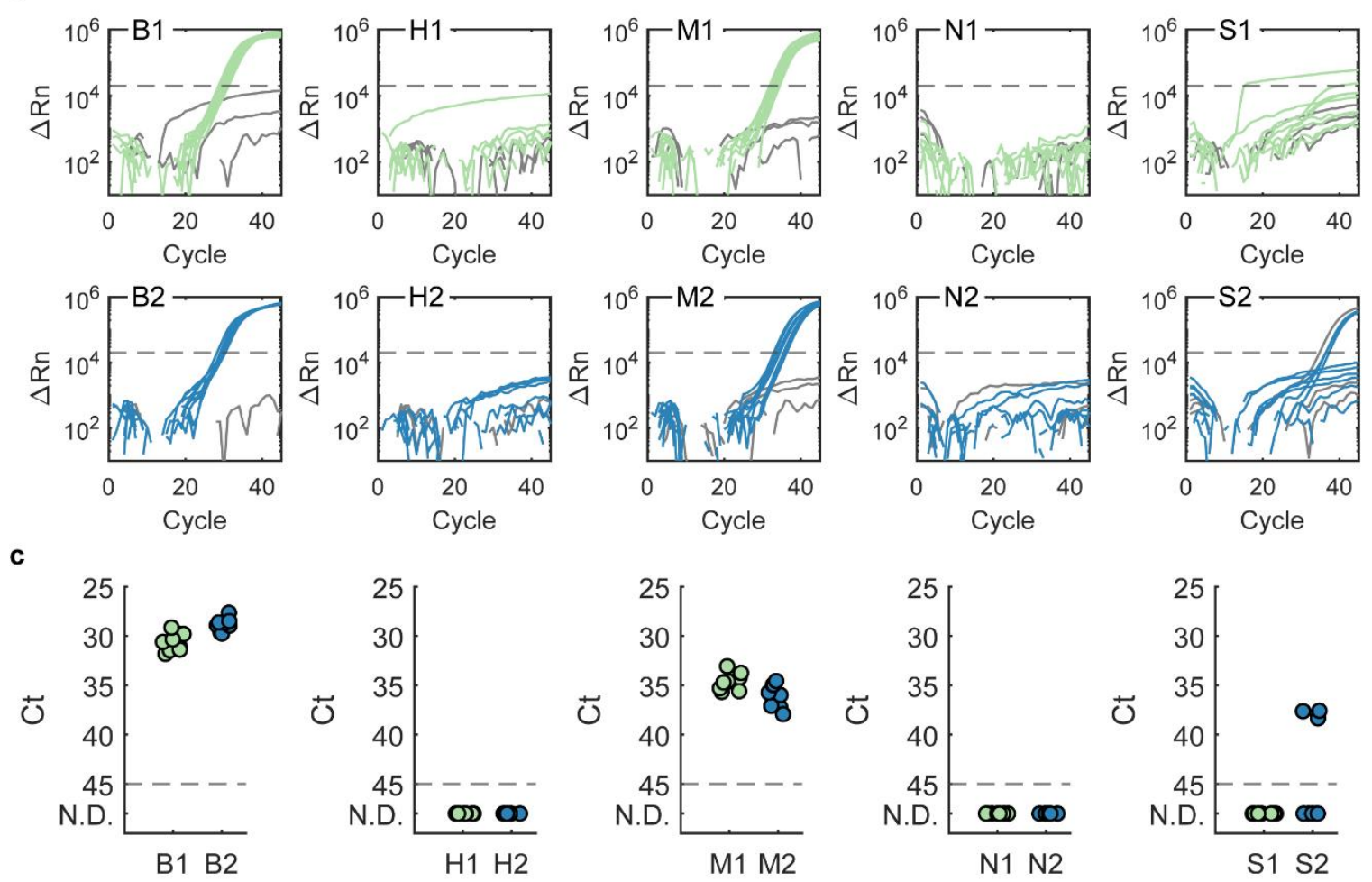

Supporting Information Figure S7. Raw qPCR data of retrieval experiments using Boolean logic. (a) Solid gray lines are no-template controls. Positive controls are different concentrations of template nucleic acid. Horizontal broken lines are amplification thresholds automatically calculated by the Quantstudio software. For Bos taurus: 1 ng, $1.5 \mathrm{ng}, 0.15 \mathrm{ng}$. For Staphylococcus aureus and Mus musculus: $10 \mathrm{ng}, 1.0 \mathrm{ng}, 0.10 \mathrm{ng}$. For Homo sapiens: $80 \mathrm{ng}$, $8.0 \mathrm{ng}, 0.80 \mathrm{ng}$ of cDNA from total RNA extracted from HEK293 cells. For SARS-CoV-2: $10^{5}, 10^{4}, 10^{3}$ viral RNA copies. (b) qPCR panel assay of retrieved sample group using FAS from the sample library. (c) Ct values calculated by the Quantstudio software. Each technical replicate (a total of three independent technical replicates) was measured in triplicates. N.D., no detected Ct. 
Supporting Information Section S12. Raw qPCR curves: retrieval of $H$. sapiens capsules using Boolean logic (200,000 capsules collected)

a
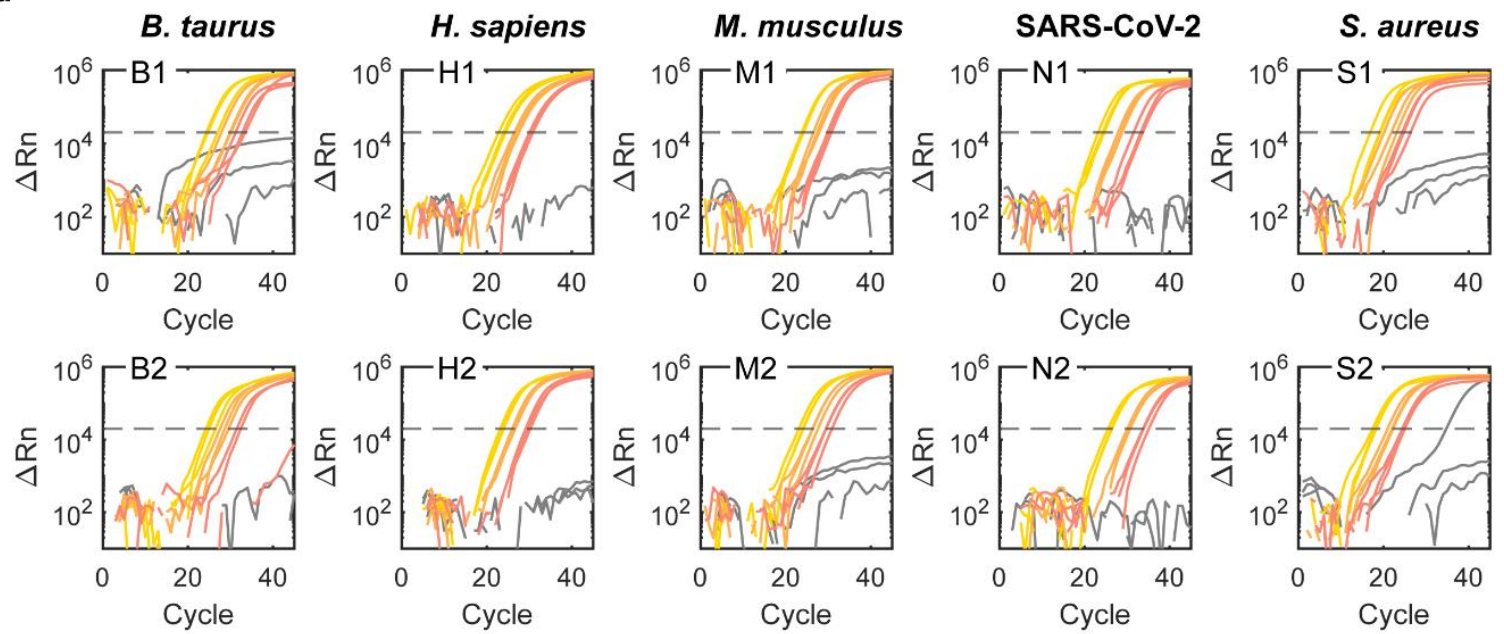

b
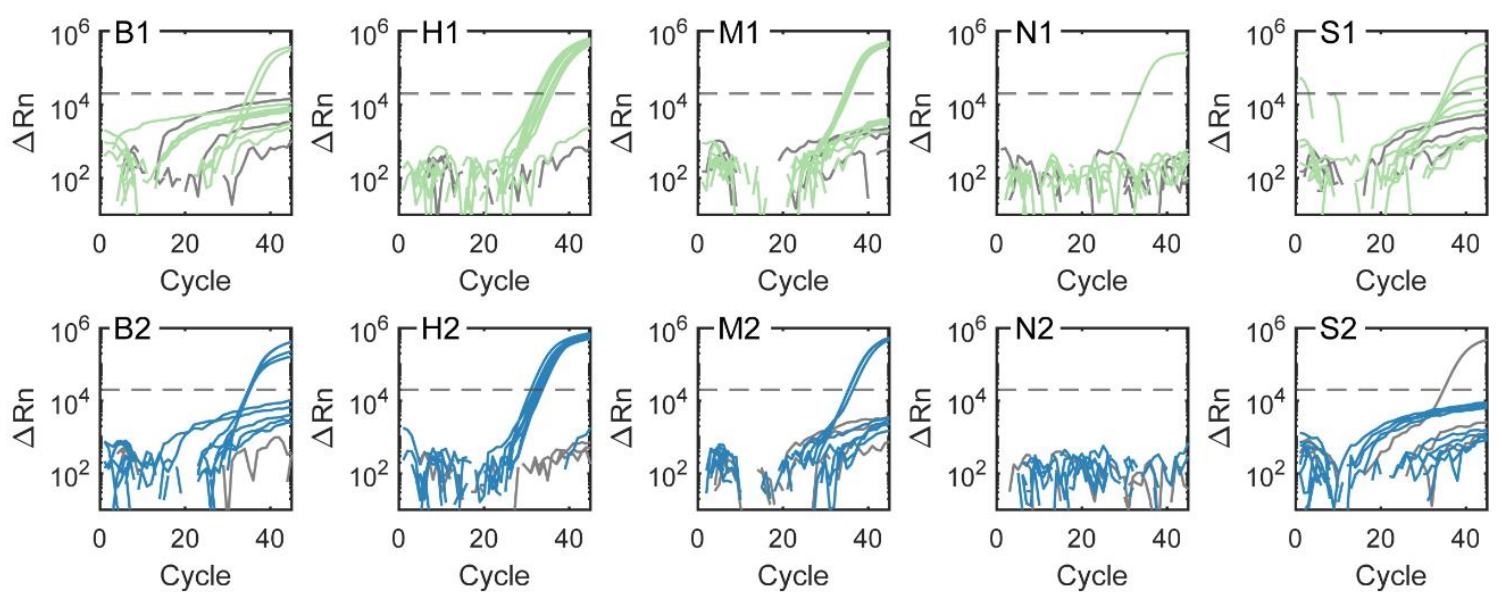

C
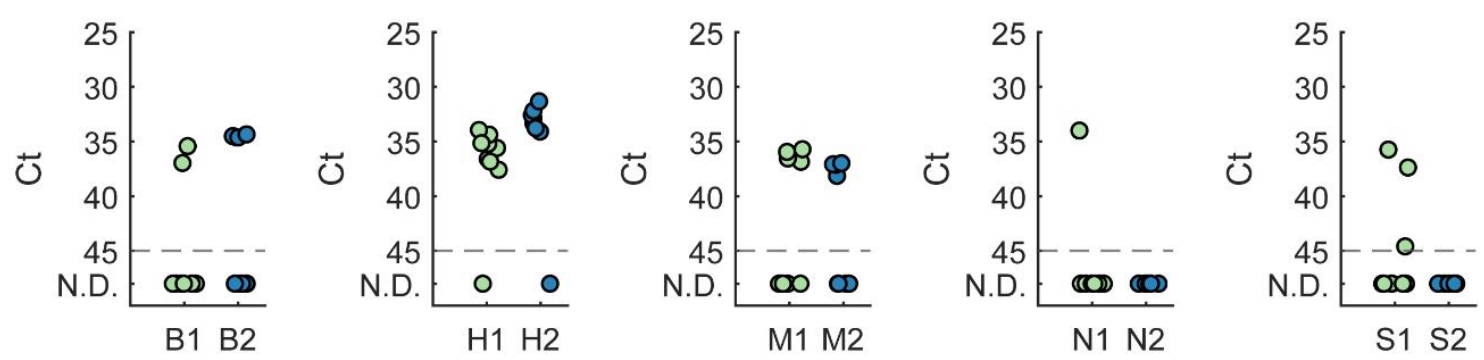

Supporting Information Figure S8. Raw qPCR data of retrieval experiments using Boolean logic: H. sapiens capsules. (a) Solid gray lines are no-template controls. Positive controls are different concentrations of template nucleic acid. Horizontal broken lines are amplification thresholds automatically calculated by the Quantstudio software. For Bos taurus: $15 \mathrm{ng}, 1.5 \mathrm{ng}, 0.15 \mathrm{ng}$. For Staphylococcus aureus and Mus musculus: $10 \mathrm{ng}, 1.0 \mathrm{ng}, 0.10$ ng. For Homo sapiens: $80 \mathrm{ng}, 8.0 \mathrm{ng}, 0.80 \mathrm{ng}$ of cDNA from total RNA extracted from HEK293 cells. For SARSCoV-2: $10^{5}, 10^{4}, 10^{3}$ viral RNA copies. (b) qPCR panel assay of retrieved sample group using FAS from the sample library. (c) Ct values calculated by the Quantstudio software. Each technical replicate (a total of three independent technical replicates) was measured in triplicates. N.D., no detected Ct. 


\section{Supporting Information Section S13. Sequencing validation}

$H$. sapiens and $S$. aureus samples were sorted and released from encapsulation as described in the "Reverse encapsulation and cleanup" subsection. For SARS-CoV-2 samples, a volume of $50 \mu \mathrm{L}$ of $1 \mathrm{mg} \mathrm{mL} \mathrm{mL}^{-1}$ was released from encapsulation and cleaned up also using the methods described in the "Reverse encapsulation and cleanup" subsection. Released $H$. sapiens and SARS-CoV-2 RNA were converted to cDNA using the same procedures described in the "cDNA conversion" subsection. Sequencing controls were derived from nucleic acid stocks that were not encapsulated and were stored in $-20{ }^{\circ} \mathrm{C}$.

Sequencing primers for SARS-CoV-2 and S. aureus were designed using Primer-BLAST from NCBI, while primers for $H$. sapiens were obtained from PrimerBank ${ }^{4-5}$. All sequencing primers contained partial Illumina ${ }^{\circledR}$ adapters (Supporting Information Table S4). Amplicons for sequencing were obtained by PCR amplification of cDNA from $H$. sapiens and SARS-CoV-2 samples or genomic $S$. aureus DNA samples using KAPA HiFi HotStart DNA polymerase (Roche Diagnostics, IN; catalog number: KK2601) for 35 cycles. Amplicons were then purified using AMPure XP magnetic particles (Beckman Coulter, IN; catalog number: A63880) and concentrations were normalized to $20 \mathrm{ng} \mu \mathrm{L}^{-1}$. Purified amplicons were submitted to GENEWIZ (South Plainfield, NJ) for amplicon-based sequencing using short-read Illumina MiSeq and independent indel/single-nucleotide polymorphism analyses.

Supporting Information Table S4. Sequencing primers. All primers were flanked with partial Illumina ${ }^{\circledR}$ adapters at the 5" end: ACACTCTTTCCCTACACGACGCTCTTCCGATCT (forward primers) and GACTGGAGTTCAGACGTGTGCTCTTCCGATCT (reverse primers).

\begin{tabular}{|c|c|c|c|c|}
\hline Species & GenBank reference & Primer sequences & Amplicon sequence & Amplicon length \\
\hline H. sapiens & NM_001101.1 & $\begin{array}{l}\text { Reverse: } \\
\text { GACTGGAGTTCAGACGTGTGCTCT } \\
\text { TCCGATCTCTCCTTAATGTCACGC } \\
\text { ACGAT }\end{array}$ & $\begin{array}{l}\text { CATGTACGTTGCTATCCAGGCTG } \\
\text { TGCTATCCCTGTACGCCTCTGGC } \\
\text { CGTACCACTGGCATCGTGATGGA } \\
\text { CTCCGGTGACGGGGTCACCCACA } \\
\text { CTGTGCCCATCTACGAGGGGTAT } \\
\text { GCCCTCCCCCATGCCATCCTGCG } \\
\text { TCTGGACCTGGCTGGCCGGGACC } \\
\text { TGACTGACTACCTCATGAAGATC } \\
\text { CTCACCGAGCGCGGCTACAGCTT } \\
\text { CACCACCACGGCCGAGCGGGAAA } \\
\text { TCGTGCGTGACATTAAGGAG }\end{array}$ & 250 \\
\hline H. sapiens & NM_001256799 & $\begin{array}{l}\text { Forward: } \\
\text { ACACTCTTCCCTACACGACGCTC } \\
\text { TTCCGATCTGGAGCGAGATCCCTC } \\
\text { CAAAAT } \\
\text { Reverse: } \\
\text { GACTGGAGTTCAGACGTGTGCTCT } \\
\text { TCCGATCTGGCTGTTGTCATACTT } \\
\text { CTCATGG }\end{array}$ & $\begin{array}{l}\text { GGAGCGAGATCCCTCCAAAATCA } \\
\text { AGTGGGGCGATGCTGGCGCTGAG } \\
\text { TACGTCGTGGAGTCCACTGGCGT } \\
\text { CTTCACCACCATGGAGAAGGCTG } \\
\text { GGGCTCATTTGCAGGGGGGAGCC } \\
\text { AAAAGGGTCATCATCTCTGCCCC } \\
\text { CTCTGCTGATGCCCCCATTTCGT } \\
\text { CATGGGTGTGAACCATGAGAAGT } \\
\text { ATGACAACAGCC }\end{array}$ & 197 \\
\hline SARS-CoV-2 & MT007544.1 & $\begin{array}{l}\text { Forward: } \\
\text { ACACTCTTTCCCTACACGACGCTC } \\
\text { TTCCGATCTCTTCGATGTCGAGGG } \\
\text { GTGTC } \\
\text { Reverse: } \\
\text { GACTGGAGTTCAGACGTGTGCTCT } \\
\text { TCCGATCTAATTGATCTCCAGGCG } \\
\text { GTGG }\end{array}$ & $\begin{array}{l}\text { CTTCGATGTCGAGGGGTGTCATG } \\
\text { CTACTAGAGAAGCTGTTGGTACC } \\
\text { AATTTACCTTTACAGCTAGGTTT } \\
\text { TTCTACAGGTGTTAACCTAGTTG } \\
\text { CTGTACCTACAGGTTATGTTGAT } \\
\text { ACACCTAATAATACAGATTTTTC } \\
\text { CAGAGTTAGTGCTAAACCACCGC } \\
\text { CTGGAGATCAATT }\end{array}$ & 174 \\
\hline SARS-CoV-2 & MT007544.1 & $\begin{array}{l}\text { Forward: } \\
\text { ACACTCTTTCCCTACACGACGCTC } \\
\text { TTCCGATCTTGGTGCTAACAAAGA } \\
\text { CGGCA }\end{array}$ & $\begin{array}{l}\text { TGGTGCTAACAAAGACGGCATCA } \\
\text { TATGGGTTGCAACTGAGGGAGCC } \\
\text { TTGAATACACCAAAAGATCACAT }\end{array}$ & 152 \\
\hline
\end{tabular}




\begin{tabular}{|c|c|c|c|c|}
\hline & & $\begin{array}{l}\text { Reverse: } \\
\text { GACTGGAGTTCAGACGTGTGCTCT } \\
\text { TCCGATCTCTGCGTAGAAGCCTTT } \\
\text { TGGC }\end{array}$ & $\begin{array}{l}\text { TGGCACCCGCAATCCTGCTAACA } \\
\text { ATGCTGCAATCGTGCTACAACTT } \\
\text { CCTCAAGGAACAACATTGCCAAA } \\
\text { AGGCTTCTACGCAG }\end{array}$ & \\
\hline \multirow[t]{2}{*}{ S. aureus } & NG_047955.1 & $\begin{array}{l}\text { Forward: } \\
\text { ACACTCTTTCCCTACACGACGCTC } \\
\text { TTCCGATCTATCAAAAATGGGTTC } \\
\text { AGCCAGA }\end{array}$ & \multirow{2}{*}{$\begin{array}{l}\text { ATCAAAAATGGGTTCAGCCAGAT } \\
\text { TCATTTGTACCAATTAAAAAGAT } \\
\text { AAATAAACAAGATGAATATATAG } \\
\text { ACAAATTAATTAAATCATACAAT } \\
\text { TTACAAATAAACACTATAAAAAG } \\
\text { CCGTGTTTATCCATTGAACGAAG } \\
\text { CAACAGTACACC }\end{array}$} & \multirow[t]{2}{*}{150} \\
\hline & & $\begin{array}{l}\text { Reverse: } \\
\text { GACTGGAGTTCAGACGTGTGCTCT } \\
\text { TCCGATCTGGTGTACTGTTGCTTC } \\
\text { GTTCA }\end{array}$ & & \\
\hline \multirow[t]{2}{*}{ S. aureus } & NC_007795.1 & $\begin{array}{l}\text { Forward: } \\
\text { ACACTCTTTCCCTACACGACGCTC } \\
\text { TTCCGATCTTTGATGATGAAAAAC } \\
\text { CGATTGCTG }\end{array}$ & \multirow{2}{*}{$\begin{array}{l}\text { TTGATGATGAAAAACCGATTGCT } \\
\text { GATATTTTAGAATTTAACTTAAA } \\
\text { AAAAGAAGGATACGATGTGTACT } \\
\text { GTGCATACGATGGTAATGATGCA } \\
\text { GTCGACTTAATTTATGAAGAAGA } \\
\text { ACCAGACATCGTATTACTAGATA } \\
\text { TCATGTTACCTGGTCGTGATGG }\end{array}$} & \multirow[t]{2}{*}{160} \\
\hline & & $\begin{array}{l}\text { Reverse: } \\
\text { GACTGGAGTTCAGACGTGTGCTCT } \\
\text { TCCGATCTCCATCACGACCAGGTA } \\
\text { ACATGA }\end{array}$ & & \\
\hline
\end{tabular}

\section{Supporting Information Section S14. Accelerated weathering of barcodes on microcapsules}

$S$. aureus samples $\left(20 \mu \mathrm{L}\right.$ of $1 \mathrm{mg} \mathrm{mL} \mathrm{m}^{-1}$ capsules) were stored in an incubator (VWR; model number: $1500 \mathrm{E}$ ) that was preset at $70{ }^{\circ} \mathrm{C}$. To generate the dried samples, S. aureus were pelleted in a $1.5-\mathrm{mL}$ Eppendorf LoBind tube by centrifugation at $2,000 \times \mathrm{g}$ for 1 minute. The supernatant was removed and 100 $\mu \mathrm{L}$ of water was added. The sedimentation and wash process were repeated two additional times with water then additional two more times with ethanol instead. The pellet was then dried using a SpeedVac SPD210 concentrator (Thermo Fisher Scientific; catalog number: SPD210-115) for 1 hour at $35{ }^{\circ} \mathrm{C}$ to ensure complete removal of ethanol. The same process was used to generate the oil-immersed samples, except the dried pellets were immersed in $100 \mu \mathrm{L}$ of silicone oil (Alfa Aesar; catalog number: A12728-22) as the endpoint for sample preparation. The dried and oil-immersed samples were capped and stored in the incubator for three months in an airtight container (Lock and Lock 54 oz. container). Relative humidity in the incubator was controlled using saturated salt solutions ${ }^{6-7}$, specifically using saturated potassium iodide solution, also stored in the container with the samples.

To test barcode integrity of the capsules, dried and oil-immersed samples were reconstituted to buffer for FAS analyses. Dried samples were reconstituted with $1 \times \mathrm{TAE}$ buffer with $500 \mathrm{mM} \mathrm{NaCl}$. For the oil-immersed samples, $500 \mu \mathrm{L}$ of $1 \times$ TAE buffer with $500 \mathrm{mM} \mathrm{NaCl}$ was added. The mixture was centrifuged at $2,000 \times \mathrm{g}$ for 30 seconds to encourage phase separation, then the top layer (oil layer) was removed (Note: a few $\mu \mathrm{L},<50 \mu \mathrm{L}$, of the buffer was also drawn to maximize the removal of oil). A volume of $200 \mu \mathrm{L}$ of toluene was then added. The resulting mixture was vortexed for 10 seconds then centrifuged at $2,000 \times \mathrm{g}$ for 30 seconds to encourage phase separation. The toluene layer was removed (Note: additional few $\mu \mathrm{L},<50 \mu \mathrm{L}$, of the buffer was also drawn to maximize the removal of toluene). The sedimentation and redispersion process using $1 \times \mathrm{TAE}$ buffer with $500 \mathrm{mM} \mathrm{NaCl}$ was repeated once to ensure no toluene remained in the mixture. Finally, a volume $500 \mu \mathrm{L}$ of $1 \times$ TAE buffer with $500 \mathrm{mM} \mathrm{NaCl}$ was added, sonicated for 5 minutes at $37 \mathrm{kHz}$ to assist the redispersion of the capsules, and transferred into a new 1.5$\mathrm{mL}$ Eppendorf LoBind tube.

To assay barcode degradation with FAS, a volume of $5 \mu \mathrm{L} " S$. aureus" probe (Supporting Information Table S2) was added to re-dispersed dried and oil-immersed samples. FAS was then performed using the methods used in the "Fluorescence activated sorting" section except the capsules were not physically sorted and only the scattering and emission data were collected. 


\section{Controls}

Day 0: no probe added

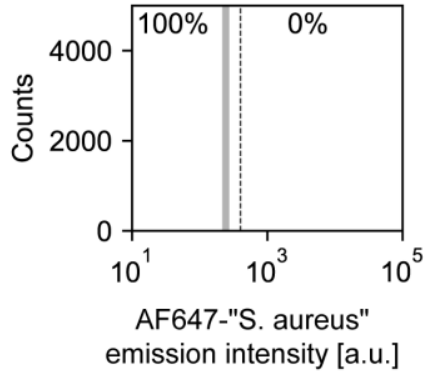

Day 0: probe added

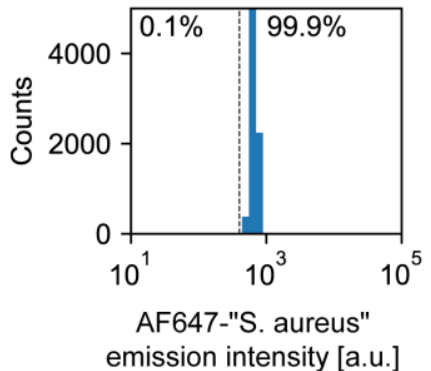

\section{Dried samples}

\section{Replicate 1}

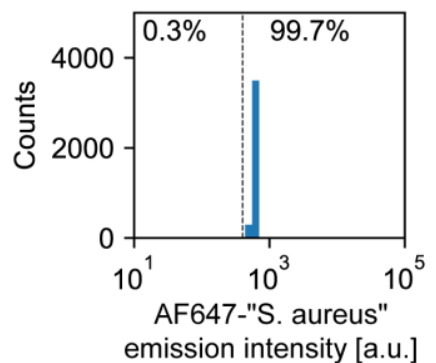

\section{Oil-immersed samples}

\section{Replicate 1}

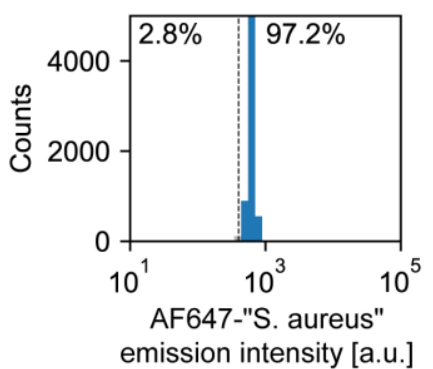

Replicate 2

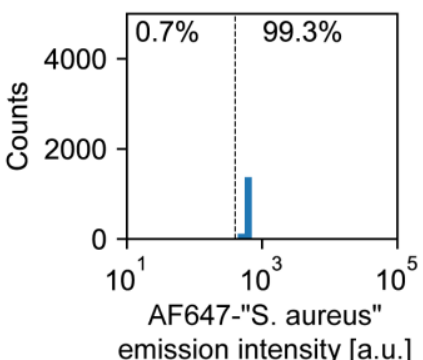

\section{Replicate 3}

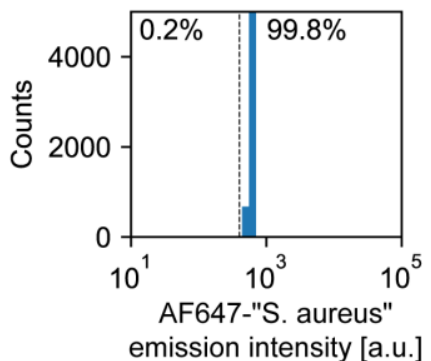

Replicate 2

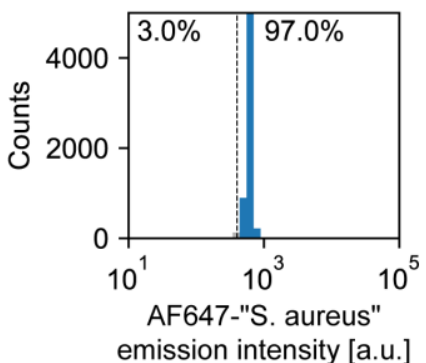

Replicate 3

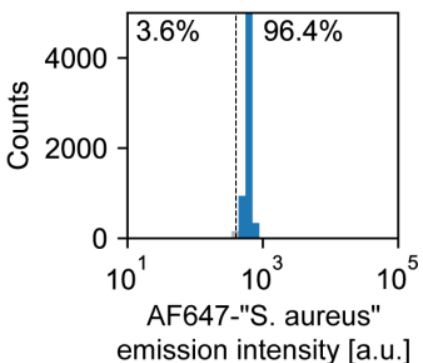

Supporting Information Figure S9. FAS data on barcode degradation after $\mathbf{7}$ days. Control samples are S. aureus capsules that were stored at room temperature at the same amount of time as the dried and oil-immersed samples. The controls were used to draw the FAS gates for analyses. All replicates are independent technical replicates. 


\section{Controls}

Day 0: no probe added

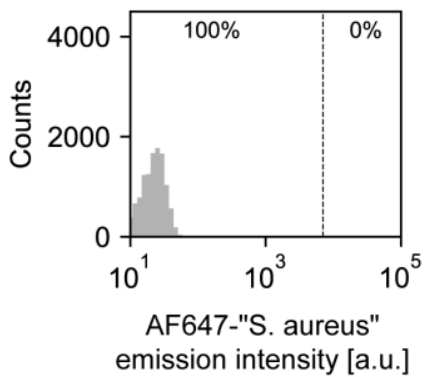

Day 0: probe added

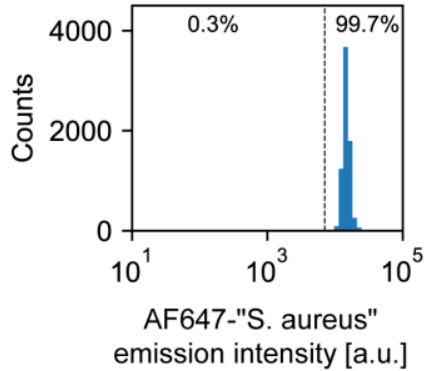

\section{Dried samples}

\section{Replicate 1}

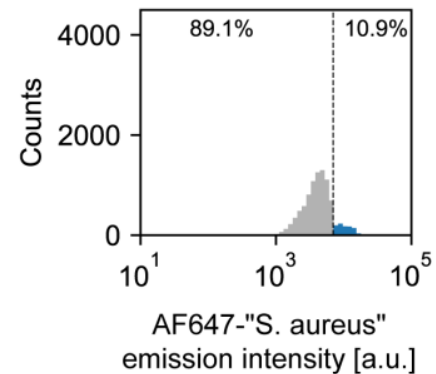

Replicate 2

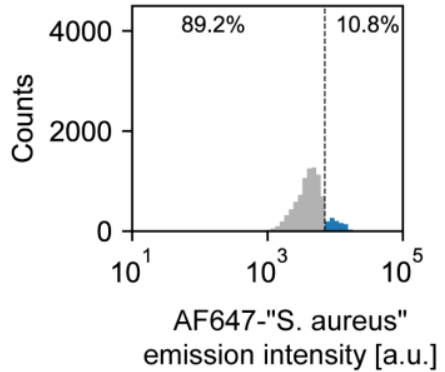

\section{Replicate 3}

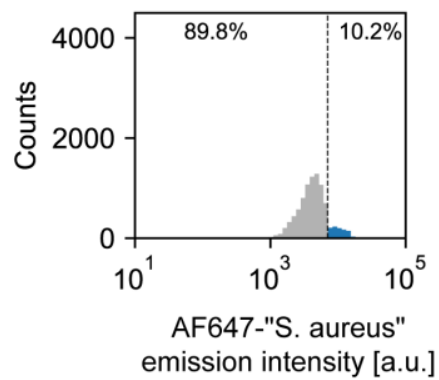

\section{Oil-immersed samples}

\section{Replicate 1}

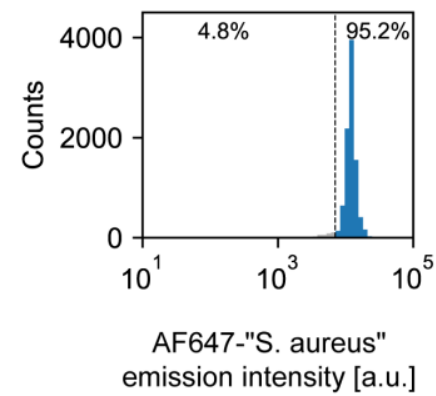

Replicate 2

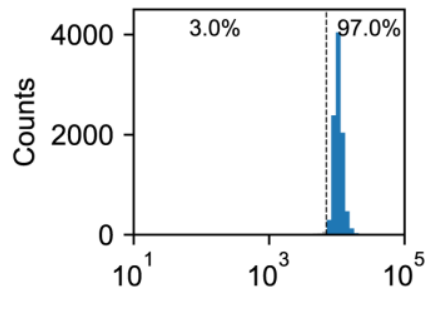

AF647-"S. aureus" emission intensity [a.u.]
Replicate 3

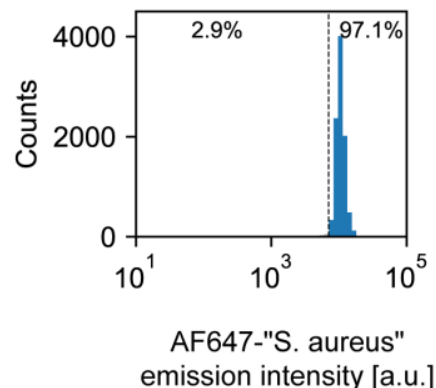

Supporting Information Figure S10. FAS data on barcode degradation after 90 days. Control samples are $S$. aureus capsules that were stored at room temperature at the same amount of time as the dried and oil-immersed samples. The controls were used to draw the FAS gates for analyses. All replicates are independent technical replicates. 


\section{References}

1. Banal, J. L.; Shepherd, T. R.; Berleant, J.; Huang, H.; Reyes, M.; Ackerman, C. M.; Blainey, P. C.; Bathe, M., Random Access DNA Memory using Boolean Search in an Archival File Storage System. Nat. Mater. 2021, 20, $1272-1280$.

2. Xu, Q.; Schlabach, M. R.; Hannon, G. J.; Elledge, S. J., Design of 240,000 Orthogonal 25mer DNA Barcode Probes. Proc. Natl. Acad. Sci. U.S.A 2009, 106, 2289-2294.

3. Ye, J.; Coulouris, G.; Zaretskaya, I.; Cutcutache, I.; Rozen, S.; Madden, T. L., Primer-BLAST: A Tool to Design Target-Specific Primers for Polymerase Chain Reaction. BMC Bioinformatics 2012, 13, Article number: 134.

4. Wang, X.; Seed, B., A PCR Primer Bank for Quantitative Gene Expression Analysis. Nucleic Acids Res. 2003, 31, Article number: e154.

5. $\quad$ Spandidos, A.; Wang, X.; Wang, H.; Seed, B., PrimerBank: A Resource of Human and Mouse PCR Primer Pairs for Gene Expression Detection and Quantification. Nucleic Acids Res. 2009, 38, D792-D799.

6. Greenspan, L., Humidity Fixed Points of Binary Saturated Aqueous Solutions. J. Res. Natl. Bur. Stand. (U. S.) $1977,81,89-96$.

7. $\quad$ Organick, L.; Nguyen, B. H.; McAmis, R.; Chen, W. D.; Kohll, A. X.; Ang, S. D.; Grass, R. N.; Ceze, L.; Strauss, K., An Empirical Comparison of Preservation Methods for Synthetic DNA Data Storage. Small Methods 2021, 5, Article number: 2001094. 